\title{
Comparative Indoor Pollution from Glo, Iqos, and Juul, Using Traditional Combustion Cigarettes as Benchmark: Evidence from the Randomized SUR-VAPES AIR Trial
}

\author{
Mariangela Peruzzi ${ }^{1,2, *,+} \oplus$, Elena Cavarretta $1,2,+\left(\mathbb{D}\right.$, Giacomo Frati ${ }^{1,3}$, Roberto Carnevale ${ }^{1,2}(\mathbb{D}$, \\ Fabio Miraldi ${ }^{4}$, Giuseppe Biondi-Zoccai ${ }^{1,2}$, Sebastiano Sciarretta ${ }^{1,3}$, Francesco Versaci ${ }^{5}$, \\ Vittoria Cammalleri ${ }^{6}$, Pasquale Avino ${ }^{7}\left(\mathbb{D}\right.$, Carmela Protano ${ }^{6}$ and Matteo Vitali ${ }^{6}$ (i) \\ 1 Department of Medico-Surgical Sciences and Biotechnologies, Sapienza University of Rome, \\ Corso della Repubblica 74, 04100 Latina, Italy; elena.cavarretta@uniroma1.it (E.C.); \\ giacomo.frati@uniroma1.it (G.F.); roberto.carnevale@uniroma1.it (R.C.); \\ giuseppe.biondizoccai@uniroma1.it (G.B.-Z.); sebastiano.sciarretta@uniroma1.it (S.S.) \\ 2 Mediterranea Cardiocentro, 80122 Naples, Italy \\ 3 IRCCS NEUROMED, 86077 Pozzilli, Italy \\ 4 Department of Clinical, Internal Medicine, Anesthesiology and Cardiovascular Sciences, \\ Sapienza University of Rome, Viale Del Policlinico 155, 00161 Rome, Italy; fabio.miraldi@uniroma1.it \\ 5 UOC UTIC Emodinamica e Cardiologia, Ospedale Santa Maria Goretti, Via Antonio Canova, \\ 04100 Latina, Italy; francescoversaci@yahoo.it \\ 6 Department of Public Health and Infectious Diseases, Sapienza University of Rome, 00185 Rome, Italy; \\ vittoria.cammalleri@uniroma1.it (V.C.); carmela.protano@uniroma1.it (C.P.); \\ matteo.vitali@uniroma1.it (M.V.) \\ 7 Department of Agricultural, Environmental and Food Sciences (DiAAA), University of Molise, \\ via De Sanctis, 86100 Campobasso, Italy; avino@unimol.it \\ * Correspondence: mariangela.peruzzi@uniroma1.it or peruzzimari75@gmail.com \\ + These authors contributed equally to this work.
}

Received: 26 June 2020; Accepted: 16 August 2020; Published: 19 August 2020

\begin{abstract}
Modified risk products (MRP) such as electronic vaping cigarettes (EVC) and heat-not-burn cigarettes (HNBC) are appealing alternatives to combustion cigarettes. Limited between- and within-device comparative data are available on MRP. We aimed at comparing indoor particulate matter (PM) emissions measured in a randomized trial enforcing standardized smoking sessions, testing different devices and flavors of MRP, using traditional combustion cigarettes (TCC) as benchmark. Overall, MRP yielded significantly lower levels of indoor PM in comparison to TCC (with median PM levels during smoking for MRP $<100 \mu \mathrm{g} / \mathrm{m}^{3}$, and for TCC $>1000 \mu \mathrm{g} / \mathrm{m}^{3}$ ). Despite this, significant differences among MRP were found, with Iqos appearing associated with a significantly lower burden of emissions for all the monitored fractions of PM, including total PM (all $p<0.05$ ). Precisely, during use, $\mathrm{PM} \leq 1 \mu \mathrm{m}\left(\mathrm{PM}_{1}\right)$ emissions were $28(16 ; 28) \mu \mathrm{g} / \mathrm{m}^{3}$ for Glo, $25(15 ; 57) \mu \mathrm{g} / \mathrm{m}^{3}$ for Iqos, and $73(15 ; 559) \mu \mathrm{g} / \mathrm{m}^{3}$ for Juul ( $p<0.001$ for Glo vs. Iqos, $p<0.001$ for Glo vs. Juul, and $p=0.045$ for Iqos vs. Juul). Exploratory within-MRP analyses suggested significant differences between flavors, favoring, for instance, Ultramarine for Glo, Bronze for Iqos, and Mango for Juul, even if results varied substantially according to individual smoker. In conclusion, leading MRP have significantly less intense and persistent effects on indoor pollution in comparison to TCC. Yet, when focusing solely on MRP, between-product and between-flavor differences appear, with quantitative estimates suggesting lower polluting effects with Iqos. These results, if confirmed externally, could be used to individualize product and flavor choice to minimize the untoward effects of EVC and HNBC on indoor pollution.
\end{abstract}


Keywords: Glo; indoor; Iqos; Juul; pollution; reduced risk product; passive smoking; smoking

\section{Introduction}

Smoking of traditional combustion cigarettes (TCC) is associated with major burdens of mortality, morbidity, and cost [1,2]. Recently, novel smoking approaches have been introduced, with very favorable market penetration, including electronic vaping cigarettes (EVC) and heat-not-burn cigarettes (HNBC) [3,4]. The popularity of EVC has considerably increased during the past decades in the United States [5] and in European countries [6]. Similarly, the use of HNBC has rapidly increased worldwide, particularly among young individuals [7]. Whether these novel modified risk products (MRP) may actually prove as reduced risk products (RRP) remains still uncertain, despite several reports suggesting that both EVC and HNBC may prove less detrimental than TCC in several dimensions [8,9].

Indeed, by minimizing combustion (HNBC) or avoiding it altogether (EVC), MRP may profoundly reduce the risks associated with smoking, for instance, by reducing emissions of particulate matter (PM) and carbon monoxide (CO) [10-14], despite still delivering nicotine, with its established detrimental clinical effects [15]. Intriguingly, while EVC would theoretically appear less toxic than HNBC given the vaporization methods, the possible presence of volatile toxic agents may undermine such purported benefits $[10,16]$. This might hold even truer when specific flavors are used, given the potential to increase exponentially the release of potentially hazardous agents, putting particularly some individuals at risk who could be more susceptible than others [17]. Accordingly, several reports have highlighted that MRP cannot be considered risk-free, given the multidimensional hazards associated with their use, chronic as well as acute [18-20].

Despite an expanding evidence base on the reduced risk of indoor pollution and ensuing passive smoking associated with MRP, comparative analyses focusing on different MRP are limited in scope and detail, as well as methodology [16,21,22]. In particular, most studies focusing on MRP published to date had one or more of the following methodological weaknesses: being non-randomized, lacking comprehensive panels of different MRP, or lacking state-of-the-art multilevel statistical models for data analysis. Moreover, few if any reports have compared MRP at large, and then, focused on MRP flavors, which may impact on short and long-term safety [23]. Recently, we have described results of a randomized trial which showed significantly lower indoor emissions of PM when using Glo (British American Tobacco, London, UK), or Iqos (Altria, Richmond, VA, USA) as HNBC and Juul (Juul Labs, San Francisco, CA, USA) as EVC, in comparison to TCC [24]. PM, a well-known toxic and carcinogen independently from its physical status (solid or liquid) and chemical composition [25], was used in such study as a global indicator of indoor air pollution. We hereby aim at providing a more poignant comparison of aggregate MRP, as well as different flavors of each MRP type, in order to expand and confirm prior findings, while capitalizing on modern state-of-the-art statistical modeling tools [26,27].

\section{Materials and Methods}

\subsection{Design and Experiment}

Details of the methodology of the SUR-VAPES AIR (Sapienza University of Rome-Vascular Assessment of Proatherosclerotic Effects of Smoking Ambient Indoor) randomized trial have been provided elsewhere [24], including the institutional funding and ethical approval (Sapienza University of Rome Identifier 3520). Briefly, after generating a randomization list with blocking based on MRP type, 7 current smokers were assigned one of the products to smoke in standardized conditions according to a 2-block set of 15 sessions each, for a total of 30 sessions (thus, yielding 15 device/flavoring combinations repeated twice). The 7 subjects recruited for the experiments were smokers of traditional cigarettes that converted to dual smoking (e.g., both TCC smokers and MRP users). The combinations of device/flavoring resulting from the randomization were as follows Glo2 (Glo with 
Neo Beryl), Iqos3 (Iqos with Heets Bronze), Glo4 (Glo with Neo Yellow), Iqos6 (Iqos with Heets Yellow), Iqos1 (Iqos with Heets Amber), Glo3 (Glo with Neo Ultramarine), Juul4 (Juul with Royal Creme), Juul3 (Juul with Mint), Juul2 (Juul with Mango), Iqos2 (Iqos with Heets Blue), Iqos5 (Iqos with Heets Turquoise), Marlboro Gold (Philip Morris International, Richmond, VA, USA, for TCC), Juul1 (Juul with Golden Tobacco), Glo1 (Glo with Neo Aegean), Iqos4 (Iqos with Heets Sienna), Iqos2 (Iqos with Heets Blue), Marlboro Gold (Philip Morris International, Richmond, VA, USA, for TCC), Iqos3 (Iqos with Bronze), Glo1 (Glo with Neo Aegean), Iqos5 (Iqos with Heets Turquoise), Juul2 (Juul with Mango), Juul4 (Juul with Royal Creme), Iqos1 (Iqos with Heets Amber), Iqos4 (Iqos with Heets Sienna), Glo2 (Glo with Beryl), Glo4 (Glo with Neo Yellow), Iqos6 (Iqos with Heets Yellow), Juul1 (Juul with Golden Tobacco), Juul3 (Juul with Mint), and Glo3 (Glo with Neo Ultramarine). Glo2 was smoked by smoker 1, Iqos3 by smoker 2, Glo4 by smoker 3, Iqos6 by smoker 4, Iqos1 by smoker 5, Glo3 by smoker 6, Juul4 by smoker 7 , and so on. Notably, part of the experiments hereby reported have already been described in Protano et al., where, however, only data from 3 smokers were included [24]. In particular, the chosen TCC is characterized by a mean content/yield of $0.5 \mathrm{mg}$ nicotine, $6 \mathrm{mg}$ tar, and $7 \mathrm{mg}$ carbon monoxide per cigarette according to Braun et al. [28].

Emissions of PM with diameter $\leq 10 \mu \mathrm{m}\left(\mathrm{PM}_{10}\right), \leq 4 \mu \mathrm{m}\left(\mathrm{PM}_{4}\right), \leq 2.5 \mu \mathrm{m}\left(\mathrm{PM}_{2.5}\right)$, and $\leq 1 \mu \mathrm{m}$ $\left(\mathrm{PM}_{1}\right)$ were continuously measured in real use conditions $5 \mathrm{~min}$ before, during, and $5 \mathrm{~min}$ after smoking each product in a room of $53 \mathrm{~m}^{3}$, with temperature and relative humidity ranging between 20 and $23^{\circ} \mathrm{C}$ and 36 and $40 \%$, respectively (Figure S1). The air exchange rate $\left(\lambda=0.69 \mathrm{~h}^{-1}\right)$ of the test room was calculated using the $\mathrm{CO}_{2}$ tracer gas technique, as previously reported [24,29-31]. During each experiment, windows and doors were maintained closed. Conversely, they were opened after each experiment until room conditions were again at initial levels of PM. The aerosol concentrations $\left(\mu \mathrm{g} / \mathrm{m}^{3}\right)$ for $\mathrm{PM}_{10}, \mathrm{PM}_{4}, \mathrm{PM}_{2.5}$, and $\mathrm{PM}_{1}$ were measured with $3 \mathrm{~s}$ time resolution, using a portable, laser-operated aerosol mass analyzer (Dusttrak II Aerosol Monitor, model 8530, TSI, 0.1-10 $\mu \mathrm{m}$ particle size range, TSI, Shoreview, MN, USA). The measurements were carried out in "cumulative" mode, including the mass of all particles smaller than or equal to the defined size. The aerosol was sampled directly through the entry of the instrument without using any tube or collector. The instrument was placed approximately $1.5 \mathrm{~m}$ above the floor level and approximately $1.5 \mathrm{~m}$ from the smoker, accruing hundreds of measurements for each smoking session (Figure S1). Twelve puffs were made for each session that lasted about 5.5 min (1 puff each thirty seconds), since the common way of smoking typically consists of 10-12 puffs of a cigarette, for a period of about 5-6 $\mathrm{min}$ [24].

\subsection{Analysis}

Descriptive analysis was based on median, 1st quartile, and 3rd quartile. Inferential analysis was based, for exploratory purposes, on a mixed linear model with Gaussian likelihood using as fixed effects, timing (before, during, or after smoking) and session identifier, and as random effects, subject identifier. Specifically, this analytical approach expands, in terms of scope and precision, the previous findings as reported by Protano et al. [24]. Exploiting such a refined analytical framework, which takes into account all measurements, recognizing in the multilevel model the individual, the session, the phase (before, during and after smoking), the MRP subtype, and the MRP type (and thus, capable of simultaneously capturing within-subject, within-session, within-MRP subtype, and within-MRP type effects, as well as between-subject, between-session, between-MRP subtype, and between-MRP type effects), we focused first on the comparison between Glo, Iqos, and Juul, using TCC as the benchmark, after log10 transformation. Then, we performed within-MRP comparisons of flavors (e.g., comparing the 6 different flavors of Iqos). Finally, we explored between-subject variability in PM emissions. Statistical significance was set at the 2-tailed 0.05 level, without multiplicity adjustments. Computations and visualizations were performed with Stata 13 (StataCorp, College Station, TX, USA) with the meglm package, and R 3.6.3 (R Foundation for Statistical Computing, Vienna, Austria) with the ggplot2 package. 


\section{Result}

Overall, MRP yielded significantly lower levels of indoor PM in comparison to TCC (Table 1). In particular, during smoking sessions, median PM levels rose to $>1000 \mu \mathrm{g} / \mathrm{m}^{3}$, with further increases due to exhalation and redistribution in the after smoking phases, at odds with median PM levels always lower than $100 \mu \mathrm{g} / \mathrm{m}^{3}$ with MRP, irrespective of the flavor or smoking phase (Tables 1-4; Table S1).

Table 1. Levels of particulate matter (PM), expressed as $\mu \mathrm{g} / \mathrm{m}^{3}$, comparing Glo, Iqos, Juul, and traditional combustion cigarettes (TCC) *.

\begin{tabular}{|c|c|c|c|c|c|c|}
\hline Device & Timing & $\mathrm{PM}_{10}$ & $\mathrm{PM}_{4}$ & $\mathrm{PM}_{2.5}$ & $\mathbf{P M}_{1}$ & Total \\
\hline \multirow{3}{*}{ Glo } & Before & $16(11 ; 24)$ & $14(10 ; 23)$ & $14(10 ; 23)$ & $14(10 ; 22)$ & $19(12 ; 29)$ \\
\hline & During & $31(19 ; 120)$ & $29(17 ; 120)$ & $28(17 ; 120)$ & $28(16 ; 28)$ & $39(24 ; 127)$ \\
\hline & After & $25(19 ; 31)$ & $25(18 ; 29)$ & $24(18 ; 29)$ & $24(18 ; 29)$ & $28(22 ; 39)$ \\
\hline \multirow{4}{*}{ Iqos } & Before & $14(11 ; 19)$ & $13(10 ; 17)$ & $13(10 ; 17)$ & $13(10 ; 17)$ & $16(12 ; 23)$ \\
\hline & During & $26(17 ; 59)$ & $25(16 ; 57)$ & $25(15 ; 57)$ & $25(15 ; 57)$ & $31(20 ; 63)$ \\
\hline & After & $25(19 ; 31)$ & $25(17 ; 30)$ & $24(17 ; 30)$ & $24(17 ; 29)$ & $28(21 ; 39)$ \\
\hline & Before & $15(13 ; 18)$ & $14(12 ; 17)$ & $14(12 ; 16)$ & $14(12 ; 16)$ & $16(14 ; 22)$ \\
\hline \multirow[t]{3}{*}{ Juul } & During & $75(17 ; 565)$ & $73(16 ; 565)$ & $73(15 ; 565)$ & $73(15 ; 559)$ & $76(20 ; 565)$ \\
\hline & After & $23(16 ; 35)$ & $22(14 ; 34)$ & $21(14 ; 33)$ & $21(14 ; 33)$ & $26(18 ; 43)$ \\
\hline & Before & $10(6 ; 12)$ & $9(5 ; 11)$ & $8(4 ; 11)$ & $8(4 ; 11)$ & $10(6 ; 14)$ \\
\hline \multirow[t]{2}{*}{ TCC } & During & $1245(392 ; 3360)$ & $1245(392 ; 3360)$ & $1245(391 ; 3360)$ & $1245(391 ; 3350)$ & $1250(401 ; 3360)$ \\
\hline & After & $1400(896 ; 1580)$ & $1390(894 ; 1580)$ & $1390(894 ; 1580)$ & $1390(892 ; 1580)$ & $1400(905 ; 1580)$ \\
\hline P Glo vs. Iqos & - & $<0.001$ & $<0.001$ & $<0.001$ & $<0.001$ & $<0.001$ \\
\hline P Glo vs. Juul & - & $<0.001$ & $<0.001$ & $<0.001$ & $<0.001$ & $<0.001$ \\
\hline P Glo vs. TCC & - & $<0.001$ & $<0.001$ & $<0.001$ & $<0.001$ & $<0.001$ \\
\hline P Iqos vs. Juul & - & 0.016 & 0.031 & 0.038 & 0.045 & 0.021 \\
\hline P Iqos vs. TCC & - & $<0.001$ & $<0.001$ & $<0.001$ & $<0.001$ & $<0.001$ \\
\hline P Juul vs. TCC & - & $<0.001$ & $<0.001$ & $<0.001$ & $<0.001$ & $<0.001$ \\
\hline
\end{tabular}

* Reported as median (1st quartile; 3rd quartile); this analysis is based on a multilevel model assuming a homogenous within-modified risk product type effect, thus, comparing all measurements from Glo with all measurements from Iqos and all measurements from Juul, taking into account, however, smoker, session, and timing; $\mathrm{PM}_{10}=\mathrm{PM}$ with diameter $\leq 10 \mu \mathrm{m} ; \mathrm{PM}_{4}=\mathrm{PM}$ with diameter $\leq 4 \mu \mathrm{m} ; \mathrm{PM}_{2.5}=\mathrm{PM}$ with diameter $\leq 2.5 \mu \mathrm{m} ; \mathrm{PM}_{1}=\mathrm{PM}$ with diameter $\leq 1 \mu \mathrm{m}$.

Table 2. Levels of particulate matter (PM), expressed as $\mu \mathrm{g} / \mathrm{m}^{3}$, comparing different flavors of Glo *.

\begin{tabular}{ccccccc}
\hline Flavor & Timing & $\mathbf{P M}_{\mathbf{1 0}}$ & $\mathbf{P M}_{\mathbf{4}}$ & $\mathbf{P M}_{\mathbf{2 . 5}}$ & PM $_{\mathbf{1}}$ & Total \\
\hline \multirow{2}{*}{ Aegean } & Before & $12(9 ; 18)$ & $10(8 ; 11)$ & $10(8 ; 11)$ & $10(8 ; 12)$ & $11(9 ; 13)$ \\
& During & $82(31 ; 277)$ & $75(22 ; 276)$ & $75(22 ; 276)$ & $75(22 ; 276)$ & $76(24 ; 277)$ \\
& After & $26(23 ; 35)$ & $24(21 ; 28)$ & $24(21 ; 28)$ & $24(21 ; 28)$ & $25(22 ; 29)$ \\
Beryl & Before & $18(10 ; 35)$ & $13(8 ; 17)$ & $13(9 ; 18)$ & $13(9 ; 18)$ & $15(10 ; 20)$ \\
& During & $39(18 ; 145)$ & $28(13 ; 128)$ & $28(14 ; 130)$ & $28(14 ; 130)$ & $30(15 ; 136)$ \\
& After & $25(16 ; 31)$ & $23(12 ; 25)$ & $23(13 ; 26)$ & $23(13 ; 26)$ & $24(14 ; 27)$ \\
Ultramarine & Before & $28(19 ; 31)$ & $23(14 ; 27)$ & $24(14 ; 27)$ & $24(15 ; 28)$ & $26(16 ; 29)$ \\
& During & $33(22 ; 59)$ & $25(17 ; 32)$ & $26(17 ; 33)$ & $26(17 ; 33)$ & $28(19 ; 37)$ \\
Yellow & After & $39(23 ; 48)$ & $27(18 ; 38)$ & $28(18 ; 39)$ & $28(19 ; 39)$ & $34(20 ; 42)$ \\
& Before & $23(14 ; 25)$ & $22(12 ; 23)$ & $22(12 ; 24)$ & $22(13 ; 24)$ & $13(22 ; 24)$ \\
P Aegean vs. Beryl & During & $36(24 ; 90)$ & $26(22 ; 82)$ & $27(22 ; 82)$ & $27(23 ; 82)$ & $29(24 ; 83)$ \\
P Aegean vs. Ultramarine & After & $29(23 ; 39)$ & $27(17 ; 29)$ & $27(18 ; 29)$ & $27(18 ; 30)$ & $28(20 ; 31)$ \\
P Aegean vs. Yellow & - & 0.001 & $<0.001$ & $<0.001$ & $<0.001$ & $<0.001$ \\
P Beryl vs. Ultramarine & - & 0.027 & 0.013 & 0.010 & 0.007 & 0.126 \\
P Beryl vs. Yellow & - & 0.049 & 0.041 & 0.036 & 0.029 & 0.114 \\
P Ultramarine vs. Yellow & - & 0.132 & 0.168 & 0.168 & 0.162 & 0.014 \\
\hline
\end{tabular}

${ }^{*}$ Reported as median (1st quartile; 3 rd quartile); $\mathrm{PM}_{10}=\mathrm{PM}$ with diameter $\leq 10 \mu \mathrm{m} ; \mathrm{PM}_{4}=\mathrm{PM}$ with diameter $\leq 4 \mu \mathrm{m}$;

$\mathrm{PM}_{2.5}=\mathrm{PM}$ with diameter $\leq 2.5 \mu \mathrm{m} ; \mathrm{PM}_{1}=\mathrm{PM}$ with diameter $\leq 1 \mu \mathrm{m}$. 
Table 3. Levels of particulate matter (PM), expressed as $\mu \mathrm{g} / \mathrm{m}^{3}$, comparing different flavors of Iqos *

\begin{tabular}{|c|c|c|c|c|c|c|}
\hline & Measurements & $\mathbf{P M}_{10}$ & $\mathrm{PM}_{4}$ & $\mathrm{PM}_{2.5}$ & $\mathbf{P M}_{1}$ & Total \\
\hline \multirow{3}{*}{ Amber } & Before & $15(14 ; 17)$ & $14(14 ; 16)$ & $14(14 ; 16)$ & $14(13 ; 15)$ & $16(14 ; 23)$ \\
\hline & During & $32(24 ; 172)$ & $31(22 ; 170)$ & $30(22 ; 170)$ & $30(22 ; 170)$ & $42(24 ; 176)$ \\
\hline & After & $24(22 ; 27)$ & $23(21 ; 26)$ & $23(21 ; 26)$ & $23(20 ; 25)$ & $25(22 ; 34)$ \\
\hline \multirow{4}{*}{ Blue } & Before & $11(6 ; 13)$ & $11(5 ; 13)$ & $11(5 ; 13)$ & $10(5 ; 13)$ & $12(6 ; 17)$ \\
\hline & During & $19(11 ; 27)$ & $17(10 ; 26)$ & $10(7 ; 26)$ & $17(10 ; 26)$ & $22(13 ; 35)$ \\
\hline & After & $14(10 ; 21)$ & $12(9 ; 19)$ & $12(9 ; 19)$ & $12(9 ; 19)$ & $16(11 ; 27)$ \\
\hline & Before & $12(10 ; 15)$ & $11(9 ; 14)$ & $10(9 ; 13)$ & $10(9 ; 13)$ & $14(11 ; 21)$ \\
\hline \multirow[t]{3}{*}{ Bronze } & During & $16(12 ; 26)$ & $14(11 ; 25)$ & $14(11 ; 25)$ & $14(11 ; 25)$ & $20(13 ; 32)$ \\
\hline & After & $20(17 ; 25)$ & $18(16 ; 24)$ & $18(15 ; 24)$ & $18(15 ; 23)$ & $23(18 ; 31)$ \\
\hline & Before & $13(9 ; 16)$ & $12(8 ; 14)$ & $12(7 ; 14)$ & $12(7 ; 14)$ & $14(11 ; 21)$ \\
\hline \multirow[t]{3}{*}{ Sienna } & During & $80(25 ; 1370)$ & $80(23 ; 1370)$ & $79(22 ; 1370)$ & $79(22 ; 1370)$ & $90(28 ; 1370)$ \\
\hline & After & $23(17 ; 27)$ & $22(15 ; 26)$ & $22(15 ; 25)$ & $22(15 ; 25)$ & $25(17 ; 30)$ \\
\hline & Before & $21(15 ; 25)$ & $20(14 ; 23)$ & $19(14 ; 23)$ & $19(14 ; 22)$ & $21(15 ; 27)$ \\
\hline \multirow[t]{3}{*}{ Turquoise } & During & $39(26 ; 51)$ & $37(24 ; 49)$ & $37(24 ; 49)$ & $37(24 ; 49)$ & $43(31 ; 61)$ \\
\hline & After & $44(34 ; 51)$ & $43(33 ; 49)$ & $42(32 ; 49)$ & $42(32 ; 49)$ & $47(35 ; 58)$ \\
\hline & Before & $20(12 ; 22)$ & $19(11 ; 22)$ & $19(10 ; 21)$ & $19(10 ; 21)$ & $21(13 ; 24)$ \\
\hline \multirow[t]{2}{*}{ Yellow } & During & $24(20 ; 33)$ & $23(19 ; 32)$ & $22(19 ; 32)$ & $22(19 ; 32)$ & $26(20 ; 42)$ \\
\hline & After & $30(28 ; 35)$ & $29(27 ; 32)$ & $29(27 ; 32)$ & $28(26 ; 32)$ & $32(28 ; 42)$ \\
\hline P Amber vs. Blue & - & $<0.001$ & $<0.001$ & $<0.001$ & $<0.001$ & $<0.001$ \\
\hline P Amber vs. Bronze & - & 0.002 & 0.003 & 0.003 & 0.004 & $<0.001$ \\
\hline P Amber vs. Sienna & - & 0.122 & 0.175 & 0.190 & 0.202 & 0.078 \\
\hline P Amber vs. Turquoise & - & 0.637 & 0.725 & 0.743 & 0.751 & 0.581 \\
\hline P Amber vs. Yellow & - & 0.102 & 0.120 & 0.125 & 0.133 & 0.032 \\
\hline P Blue vs. Bronze & - & 0.373 & 0.353 & $<0.001$ & 0.366 & 0.403 \\
\hline P Blue vs. Sienna & - & $<0.001$ & $<0.001$ & 0.353 & $<0.001$ & $<0.001$ \\
\hline P Blue vs. Turquoise & - & $<0.001$ & $<0.001$ & $<0.001$ & $<0.001$ & $<0.001$ \\
\hline P Blue vs. Yellow & - & 0.020 & 0.019 & $<0.001$ & 0.022 & 0.027 \\
\hline P Bronze vs. Sienna & - & $<0.001$ & $<0.001$ & $<0.001$ & $<0.001$ & $<0.001$ \\
\hline P Bronze vs. Turquoise & - & $<0.001$ & $<0.001$ & $<0.001$ & $<0.001$ & $<0.001$ \\
\hline P Bronze vs. Yellow & - & 0.001 & 0.001 & 0.001 & 0.001 & 0.006 \\
\hline P Sienna vs. Turquoise & - & 0.247 & 0.279 & 0.290 & 0.301 & 0.195 \\
\hline P Sienna vs. Yellow & - & 0.001 & 0.003 & 0.003 & 0.004 & $<0.001$ \\
\hline P Turquoise vs. Yellow & - & $<0.001$ & $<0.001$ & 0.001 & 0.001 & $<0.001$ \\
\hline
\end{tabular}

* Reported as median (1st quartile; 3rd quartile); $\mathrm{PM}_{10}=\mathrm{PM}$ with diameter $\leq 10 \mu \mathrm{m} ; \mathrm{PM}_{4}=\mathrm{PM}$ with diameter $\leq 4 \mu \mathrm{m}$;

$\mathrm{PM}_{2.5}=\mathrm{PM}$ with diameter $\leq 2.5 \mu \mathrm{m} ; \mathrm{PM}_{1}=\mathrm{PM}$ with diameter $\leq 1 \mu \mathrm{m}$.

Table 4. Levels of particulate matter (PM), expressed as $\mu \mathrm{g} / \mathrm{m}^{3}$, comparing different flavors of Juul *.

\begin{tabular}{|c|c|c|c|c|c|c|}
\hline & Measurements & $\mathbf{P M}_{10}$ & $\mathrm{PM}_{4}$ & $\mathbf{P M}_{2.5}$ & $\mathbf{P M}_{1}$ & Total \\
\hline \multirow{4}{*}{ Golden Tobacco } & Before & $17(9 ; 19)$ & $17(8 ; 19)$ & $16(8 ; 18)$ & $16(8 ; 18)$ & $18(9 ; 22)$ \\
\hline & During & $216(61 ; 1280)$ & $214(61 ; 1270)$ & $214(61 ; 1270)$ & $214(60 ; 1270)$ & $221(63 ; 1280)$ \\
\hline & After & $22(13 ; 36)$ & $22(12 ; 34)$ & $21(12 ; 34)$ & $21(11 ; 34)$ & $24(19 ; 44)$ \\
\hline & Before & $15(12 ; 17)$ & $14(11 ; 16)$ & $14(11 ; 15)$ & $13(10 ; 15)$ & $15(12 ; 22)$ \\
\hline \multirow[t]{3}{*}{ Mango } & During & $20(13 ; 200)$ & $17(11 ; 199)$ & $16(11 ; 199)$ & $16(11 ; 195)$ & $34(14 ; 212)$ \\
\hline & After & $21(13 ; 35)$ & $20(11 ; 34)$ & $20(11 ; 33)$ & $19(11 ; 33)$ & $25(16 ; 46)$ \\
\hline & Before & $15(14 ; 17)$ & $14(14 ; 15)$ & $14(13 ; 15)$ & $14(13 ; 15)$ & $15(14 ; 19)$ \\
\hline \multirow[t]{3}{*}{ Mint } & During & $26(17 ; 304)$ & $25(14 ; 304)$ & $25(15 ; 304)$ & $25(15 ; 300)$ & $42(20 ; 314)$ \\
\hline & After & $23(18 ; 34)$ & $22(16 ; 34)$ & $22(16 ; 33)$ & $22(16 ; 32)$ & $26(19 ; 39)$ \\
\hline & Before & $15(14 ; 17)$ & $15(13 ; 16)$ & $15(13 ; 16)$ & $14(13 ; 16)$ & $16(15 ; 23)$ \\
\hline \multirow[t]{2}{*}{ Royal Crème } & During & $50(17 ; 529)$ & $50(16 ; 527)$ & $49(15 ; 526)$ & $48(15 ; 521)$ & $60(19 ; 538)$ \\
\hline & After & $25(17 ; 36)$ & $23(15 ; 34)$ & $22(15 ; 33)$ & $22(15 ; 32)$ & $28(20 ; 47)$ \\
\hline P Golden Tobacco vs. Mango & - & 0.055 & 0.042 & 0.039 & 0.035 & 0.140 \\
\hline P Golden Tobacco vs. Mint & - & 0.588 & 0.578 & 0.570 & 0.526 & 0.519 \\
\hline $\begin{array}{l}\text { P Golden Tobacco vs. } \\
\text { Royal Crème }\end{array}$ & - & 0.593 & 0.608 & 0.598 & 0.640 & 0.712 \\
\hline P Mango vs. Mint & - & 0.125 & 0.100 & 0.096 & 0.100 & 0.339 \\
\hline$P$ Mango vs. Royal Crème & - & 0.008 & 0.006 & 0.005 & 0.005 & 0.045 \\
\hline P Mint vs. Royal Crème & - & 0.152 & 0.155 & 0.145 & 0.143 & 0.177 \\
\hline
\end{tabular}

* Reported as median (1st quartile; 3 rd quartile); $\mathrm{PM}_{10}=\mathrm{PM}$ with diameter $\leq 10 \mu \mathrm{m} ; \mathrm{PM}_{4}=\mathrm{PM}$ with diameter $\leq 4 \mu \mathrm{m}$;

$\mathrm{PM} 2.5=\mathrm{PM}$ with diameter $\leq 2.5 \mu \mathrm{m} ; \mathrm{PM}_{1}=\mathrm{PM}$ with diameter $\leq 1 \mu \mathrm{m}$.

Notwithstanding the limited overall indoor contamination associated with MRP in comparison to TCC, between- and within-MRP comparative analysis showed significant differences in PM emissions (Table 1, Figure 1). 


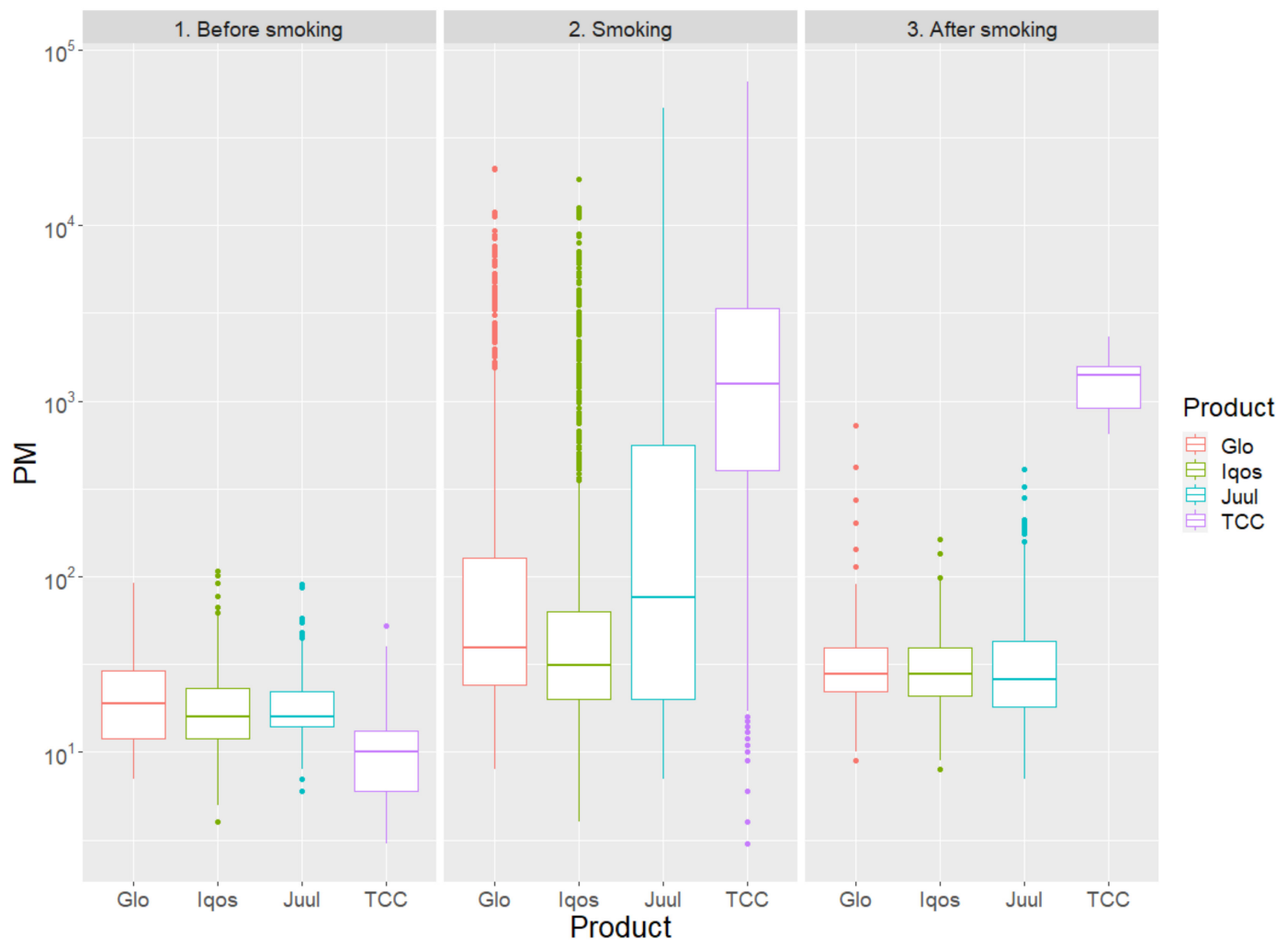

Figure 1. Total particulate matter (PM) concentrations, expressed as $\mu \mathrm{g} / \mathrm{m}^{3}$, comparing Glo, Iqos, Juul, and traditional combustion cigarettes (TCC), distinguishing the following phases: before smoking (1), smoking (2), and after smoking (3).

Specifically, Iqos appeared associated with a significantly lower burden of emissions for all classes of PM, including total PM emissions (all $p<0.05$ ), even if differences were of relatively small magnitude, and substantial variability and skewness were evident. In addition, PM concentrations quickly decreased after use with all MRP. Precisely, total PM concentrations measured in the test room during use were $39(24 ; 127) \mu \mathrm{g} / \mathrm{m}^{3}$ for Glo, $31(20 ; 63) \mu \mathrm{g} / \mathrm{m}^{3}$ for Iqos, and $76(20 ; 565) \mu \mathrm{g} / \mathrm{m}^{3}$ for Juul ( $p<0.001$ for Glo vs. Iqos, $p<0.001$ for Glo vs. Juul, and $p=0.021$ for Iqos vs. Juul), actually profiling Iqos as less polluting and Glo as more polluting. Similar effects were found for $\mathrm{PM}_{10}, \mathrm{PM}_{4}, \mathrm{PM}_{2.5}$, and $\mathrm{PM}_{1}($ all $p<0.05)$.

Within-MRP comparisons provided evidence that flavorings may impact PM indoor emissions, either because of smoke features or because of different smoking patterns (e.g., puff frequency and depth, or nasal vs. oral expiration), for all types of MRP under investigation. In particular, different Glo flavors were associated with significant differences in PM emissions (Table 2, Figure 2), with Ultramarine being associated with the lowest levels of PM of any size, at odds, for instance, with Aegean (e.g., for $\mathrm{PM}_{10}$ concentrations during use, which were, respectively, $33(22 ; 59)$ vs. $\left.82(31 ; 277) \mu \mathrm{g} / \mathrm{m}^{3}, p=0.027\right)$.

Similar analyses were conducted for Iqos (Table 3, Figure 3), highlighting that the Bronze flavor was associated with the lowest PM emissions, at odds, for instance, with Sienna, which yielded the highest concentrations of indoor PM (e.g., for $\mathrm{PM}_{2.5}$ concentrations during use, which were, respectively, $14(11 ; 25)$ vs. $\left.79(22 ; 1370) \mu \mathrm{g} / \mathrm{m}^{3}, p<0.001\right)$.

Even for Juul, between-flavor differences appeared significant, at least in terms of nominal statistical thresholds (Table 4, Figure 4). In particular, across the four flavors tested, Mango was associated with the lowest emissions of PM, at odds in particular with Golden Tobacco, which appeared associated with almost twice larger emissions (e.g., $\mathrm{PM}_{4}$ levels during use were, respectively, 17 (11; 199) vs. $\left.214(61 ; 1270) \mu \mathrm{g} / \mathrm{m}^{3}, p=0.042\right)$. 


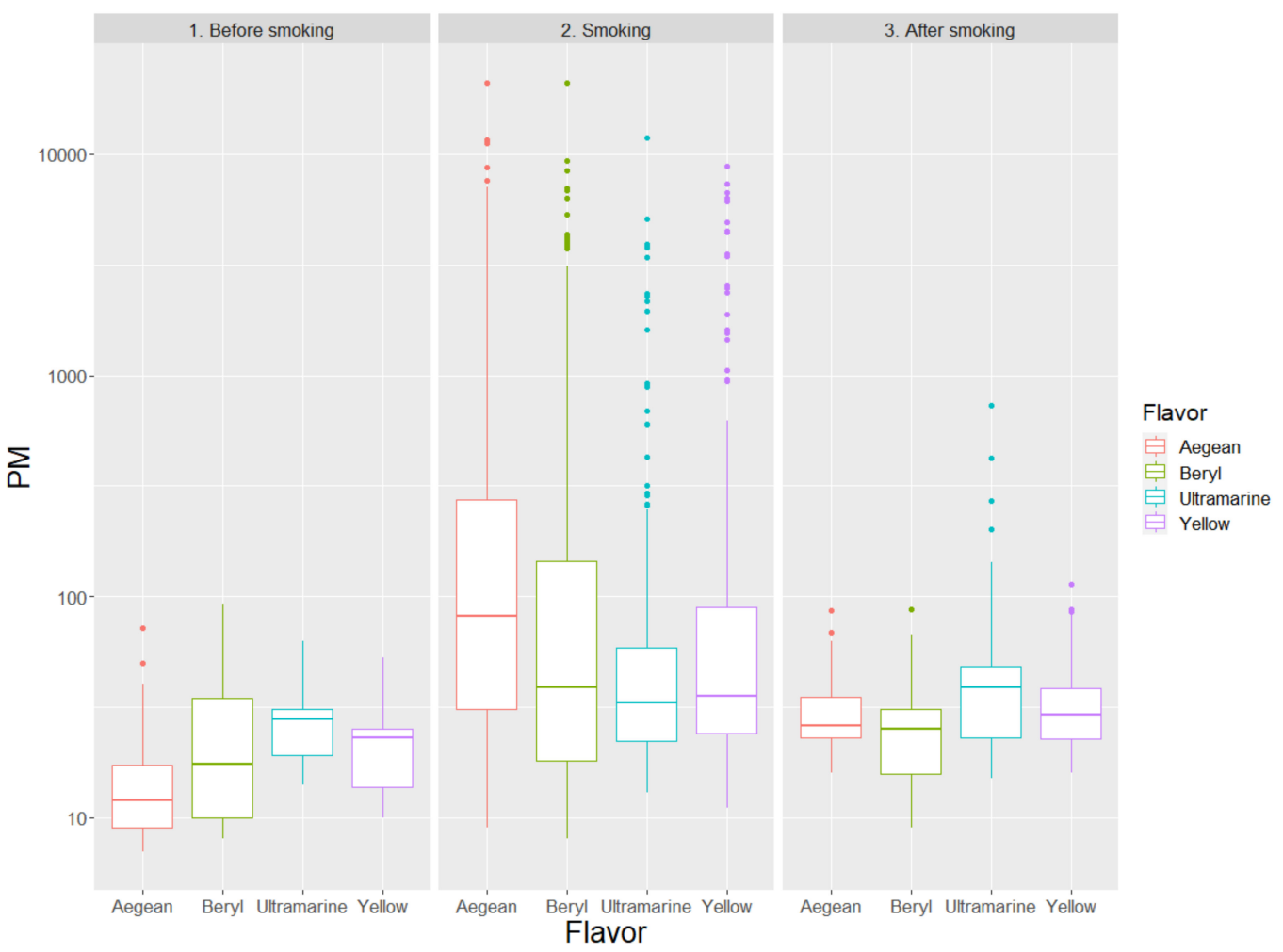

Figure 2. Levels of total particulate matter (PM), expressed as $\mu \mathrm{g} / \mathrm{m}^{3}$, comparing different flavors of Glo, distinguishing the following phases: before smoking (1), smoking (2), and after smoking (3).

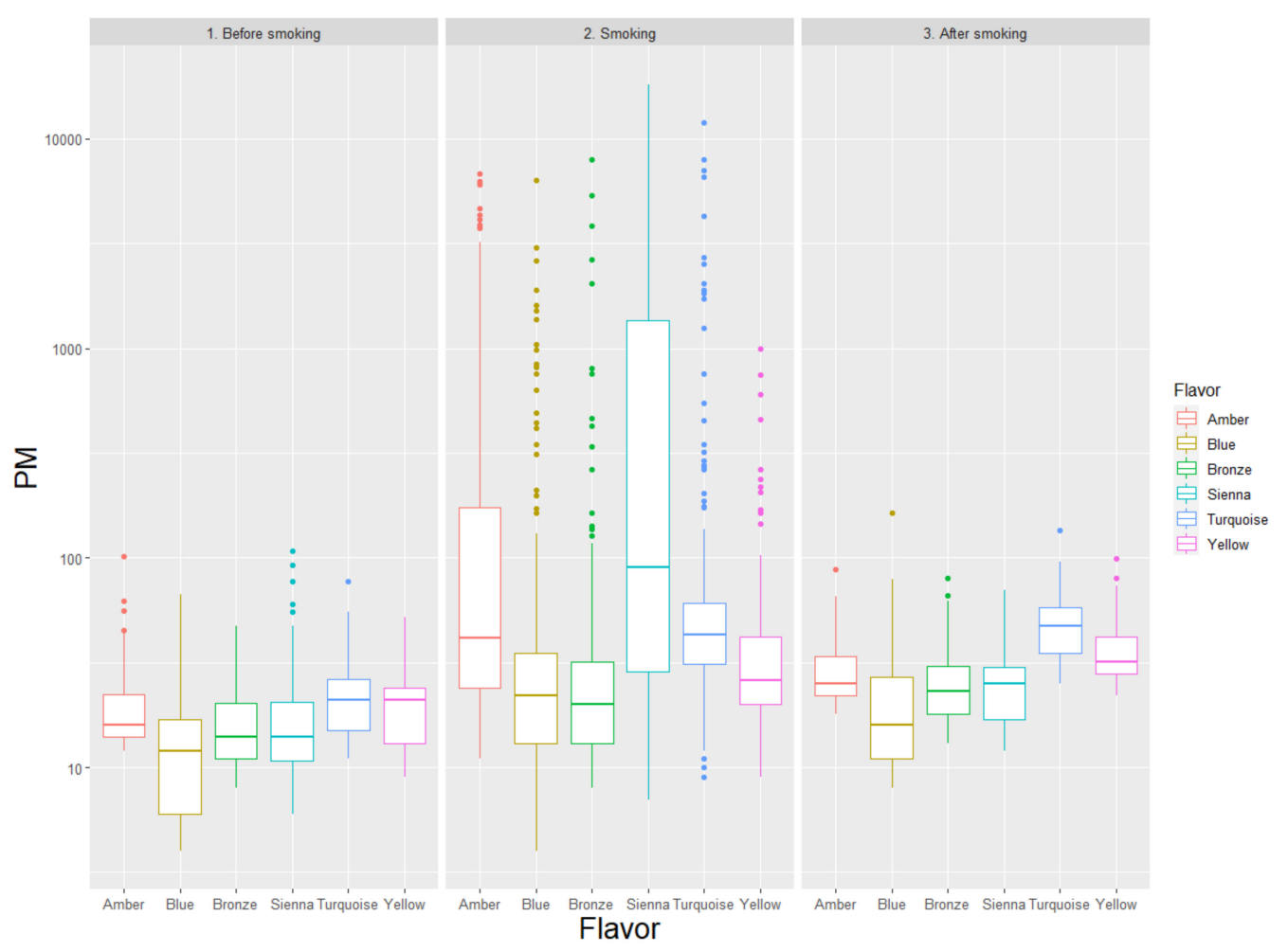

Figure 3. Levels of total particulate matter (PM), expressed as $\mu \mathrm{g} / \mathrm{m}^{3}$, comparing different flavors of Iqos, distinguishing the following phases: before smoking (1), smoking (2), and after smoking (3). 


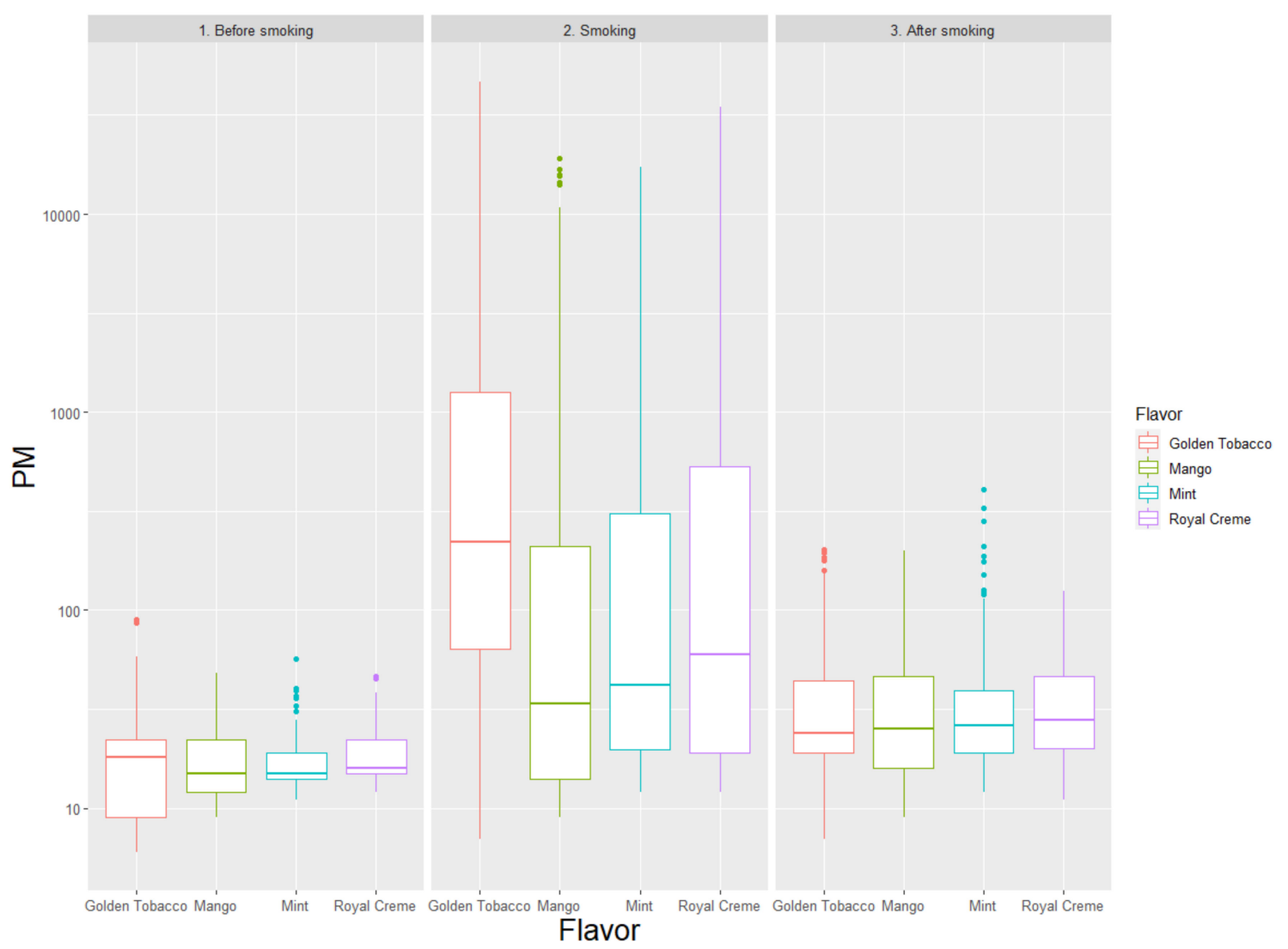

Figure 4. Levels of total particulate matter (PM), expressed as $\mu \mathrm{g} / \mathrm{m}^{3}$, comparing different flavors of Juul, distinguishing the following phases: before smoking (1), smoking (2), and after smoking (3).

Finally, exploratory analysis for between-smoker differences highlighted significant differences and variability in patterns of emissions, with some smokers generating lower PM concentrations, and others, higher PM concentrations, in some cases, with significant variability and skewness (Table S1, $p<0.001$ ).

\section{Discussion}

The present work, building upon a randomized trial comparing different leading MRP and focusing on indoor pollution in a standardized experimental setting, has the following major implications. First, the MRP under investigation in the present study, i.e., Glo, Iqos, and Juul, are associated with trivial increases in indoor pollution in comparison to TCC. Second, notwithstanding the limited impact of indoor MRP use on indoor PM concentrations, statistically significant differences between Glo, Iqos, and Juul in terms of indoor pollution appear evident, with Iqos appearing less polluting and Glo more polluting, at least in relative terms. Third, within each MRP type, flavor may impact on polluting effects, either because of smoke features or because of indirect effects mediated by smoking patterns (e.g., nasal vs. oral expiration). Fourth, there remains substantial individual variability, such that indoor pollution may be high when MRP are used by some smokers, and low when used by others. Fifth, we cannot provide a consistent explanation concerning between-flavor variability such as in the case of the less polluting effects of Iqos Bronze. We can speculate that, as in the case of TCC, menthol, by having local anesthetic properties, could conceal the negative sensations of smoking, due to desensitizing receptors [32]. Accordingly, smokers could hold their breath more and thus, reduce emissions during expiration. Irrespective of these potential confounding effects, our findings have important implications in the sense that may help, if confirmed externally in larger series, smokers 
wishing to use MRP as a risk reduction strategy (i.e., to quit altogether TCC), to pick the one which is less likely to be harmful, at least in terms of indoor pollution [33].

The evidence base on MRP is expanding exponentially, and it is clear that, despite ongoing efforts at regulating their use (e.g., with increased taxation), MRP usage will continue to grow $[3,8,9,34]$. Accordingly, it is paramount to expand the evidence concerning these products, with details worth being sought ranging from cardiovascular effects to additivity and polluting impact. Indeed, while the dramatic and persisting indoor polluting effect of TCC is very clear, MRP also adversely modify indoor ambient air [20], for instance, by releasing PM and other established or potentially toxic agents [35]. This holds true for HNBC as well as EVC, despite their evident inherent differences [35,36]. In particular, it is established that even single usage of MRP increases indoor PM levels significantly [36]. Our work builds upon such findings and provides, to date, the first thorough comparison between two leading HNBC, Glo and Iqos, with a leading EVC, Juul. Interestingly, MRP appear unequal in terms of indoor polluting effects, in the sense that in our study, Iqos was associated with less indoor polluting effects than Glo and, albeit to a lesser extent, Juul. Accordingly, indoor pollution associated with MRP is not MRP-type specific, but rather, device-specific.

Furthermore, building upon accruing evidence suggesting the impact of different flavors of a given $\mathrm{MRP}$ on its risk profile, we explored within-device (i.e., between-flavor) polluting effects, finding indeed that some flavors are associated with more indoor pollution than others [37-45]. Notwithstanding the evident impact of smoker features (which may range from habitus to cardiopulmonary physiology or smoking style), it is clear that MRP should not be considered all identical, and even specific flavors may be more or less hazardous than others $[38,41]$. Indeed, differences in exhaled aerosols from different smokers depend on many factors, including individual characteristics (i.e., age, gender, lung capacity) and status (stress, anxiety, time since the last cigarette, nicotine addiction degree, etc.), in addition to the specific way of smoking (puff frequency, intensity, volume, and duration at different stages of cigarette consumption, as well as breath hold) [46]. Thus, different smokers/vapers generated different shapes of exhaled aerosol, but this is a common limitation of all experiments performed by humans. Despite these interesting results, further research is required to expand our findings. In particular, a larger sample is required for external validation. In addition, other dimensions of toxicity should be appraised (e.g., aromatic cyclic compounds or heavy metals). Similarly, mitigating factors will need careful appraisal, such as ambient volume, impact of aeration, and so forth. Finally, the association between passive and active smoking effects remains the focus of intense research [47], especially when considering also other established and cardiovascular risk factors [48].

An important issue of our work is the applicability of our findings on Iqos to other HNBC, and, similarly, on Juul to other EVC. In fact, other HNBC devices are available in selected markets, with underlying mechanisms to heat tobacco that differ, at least in part, from Glo and Iqos. Given the evident differences between Glo and Iqos hereby described, we can expect that PM emissions may be specific to each HNBC type, and even its flavors. Similar arguments may apply to EVC. Indeed, we chose Juul for this trial because, on top of being an established market player, it is characterized by default standardization of aerosol emissions. Many EVC can, however, let users customize exposure, in terms of both solution components, concentration, and volume. Accordingly, we cannot safely recommend extrapolating our results on Juul towards other EVC. Accordingly, most likely some EVC may prove significantly more harmful than Juul in terms of toxic emissions [49,50].

This work has several drawbacks, which range from the small sample size to the focus on only three MRP. In addition, apparently healthy volunteers participated in the trial, and thus, our results cannot be considered immediately applicable to patients with cardiopulmonary disease. Notably, differences in indoor polluting effects, while often statistically significant, were of modest magnitude betweenand within-MRP, especially when compared to the much greater impact of TCC, and thus, their clinical impact remains to be determined [51]. In addition, we focused our measurements only on PM, but the potential scope of toxic agents released by MRP is very wide, and thus, additional studies with a multidimensional measurement scope are required. Moreover, in vitro experimental studies should 
be performed to assess whether the observed indoor PM concentrations could increase inflammation and oxidative stress. Furthermore, it is evident that Juul mostly emits liquid droplets, whereas PM produced by HNBC consists of largely solid material. Finally, different analytical approaches can yield different comparative and inferential estimates, given the clear impact of focusing only on smoking sessions vs. more comprehensive pre-, during- and post-smoking sessions, as clearly showed by the differences between the present work and Protano et al. [24]. Yet, it remains undisputed that MRP cannot be considered equal in terms of PM indoor emissions, in terms of both between- and within-MRP comparisons.

\section{Conclusions}

Leading MRP such as Glo, Iqos, and Juul have significantly less intense and persistent effects on indoor pollution in comparison to TCC. Yet, when focusing solely on MRP, between-product and between-flavor differences appear, with quantitative estimates suggesting lower polluting effects with Iqos. These results, if confirmed externally, could be used to individualize product and flavor choice to minimize the untoward effects of EVC and HNBC.

Supplementary Materials: The following are available online at http://www.mdpi.com/1660-4601/17/17/6029/s1, Figure S1. Example of measurements obtained during a single-modified risk product subtype smoking session by an individual smoker, totalling 262 values. Left panel highlights measurements before smoking, middle panel measurements during smoking, and right panel measurements after smoking, for a total time of $13 \mathrm{~min}$. In the present case, a Glo Aegean was used. $\mathrm{PM}_{10}=\mathrm{PM}$ with diameter $\leq 10 \mu \mathrm{m} ; \mathrm{PM}_{4}=\mathrm{PM}$ with diameter $\leq 4 \mu \mathrm{m}$; $\mathrm{PM}_{2.5}=\mathrm{PM}$ with diameter $\leq 2.5 \mu \mathrm{m} ; \mathrm{PM}_{1}=\mathrm{PM}$ with diameter $\leq 1 \mu \mathrm{m}$., Table S1. Levels of particulate matter (PM), expressed as $\mu \mathrm{g} / \mathrm{m} 3$, comparing different smokers.

Author Contributions: Conceptualization, M.P. and G.B.-Z.; methodology, V.C., P.A., C.P., and M.V.; software and data curation, M.P., E.C., V.C., and C.P.; validation, G.B.-Z., and F.V.; formal analysis, M.P., E.C., G.F., and G.B.-Z.; writing-original draft preparation, M.P., E.C., and G.B.-Z.; writing-review and editing, G.F., R.C., F.M., F.V., V.C., P.A., C.P., and M.V.; supervision, G.F., R.C., F.M., G.B.-Z., S.S., F.V., and M.V. All authors have read and agreed to the published version of the manuscript.

Funding: This research received no external funding.

Conflicts of Interest: G.B.Z. has consulted for InnovHeart, Milan, Italy, and Replycare, Rome, Italy. The rest of the authors declare no conflict of interest.

\section{References}

1. GBD 2015 Tobacco Collaborators. Smoking prevalence and attributable disease burden in 195 countries and territories, 1990-2015: A systematic analysis from the Global Burden of Disease Study 2015. Lancet 2017, 389, 1885-1906. [CrossRef]

2. Weishaar, H.B.; Ikegwuonu, T.; Smith, K.E.; Buckton, C.H.; Hilton, S. E-Cigarettes: A Disruptive Technology? An Analysis of Health Actors' Positions on E-Cigarette Regulation in Scotland. Int. J. Environ. Res. Public Health 2019, 16, 3103. [CrossRef] [PubMed]

3. Fairchild, A.L.; Lee, J.S.; Bayer, R.; Curran, J. E-Cigarettes and the Harm-Reduction Continuum. N. Engl. J. Med. 2018, 378, 216-219. [CrossRef] [PubMed]

4. Lüdicke, F.; Ansari, S.M.; Lama, N.; Blanc, N.; Bosilkovska, M.; Donelli, A.; Picavet, P.; Baker, G.; Haziza, C.; Peitsch, M.; et al. Effects of Switching to a Heat-Not-Burn Tobacco Product on Biologically Relevant Biomarkers to Assess a Candidate Modified Risk Tobacco Product: A Randomized Trial. Cancer Epidemiol. Biomarkers Prev. 2019, 28, 1934-1943. [CrossRef] [PubMed]

5. Huang, J.; Duan, Z.; Kwok, J.; Binns, S.; Vera, L.E.; Kim, Y.; Szczypka, G.; Emery, S.L. Vaping versus JUULing: How the extraordinary growth and marketing of JUUL transformed the US retail e-cigarette market. Tob. Control 2018, 28, 146-151. [CrossRef]

6. Al-Hamdani, M.; Hopkins, D.B.; Park, T. Vaping among youth and young adults: A "red alert" state. J. Public Health Policy 2020, 41, 63-69. [CrossRef]

7. Ratajczak, A.; Jankowski, P.; Strus, P.; Feleszko, W. Heat Not Burn Tobacco Product-A New Global Trend: Impact of Heat-Not-Burn Tobacco Products on Public Health, a Systematic Review. Int. J. Environ. Res. Public Health 2020, 17, 409. [CrossRef] 
8. Gentry, S.; Forouhi, N.G.; Notley, C. Are Electronic Cigarettes an Effective Aid to Smoking Cessation or Reduction Among Vulnerable Groups? A Systematic Review of Quantitative and Qualitative Evidence. Nicotine. Tob. Res. 2019, 21, 602-616. [CrossRef]

9. Gilmore, A.B.; Hartwell, G. E-cigarettes: Threat or opportunity? Eur. J. Public Health 2014, 24, 532-533. [CrossRef]

10. Shein, M.; Jeschke, G. Comparison of Free Radical Levels in the Aerosol from Conventional Cigarettes, Electronic Cigarettes, and Heat-Not-Burn Tobacco Products. Chem. Res. Toxicol. 2019, 32, 1289-1298. [CrossRef]

11. Savdie, J.; Canha, N.; Buitrago, N.; Almeida, S.M. Passive Exposure to Pollutants from a New Generation of Cigarettes in Real Life Scenarios. Int. J. Environ. Res. Public Health 2020, 17, 3455. [CrossRef]

12. Bitzer, Z.T.; Goel, R.; Trushin, N.; Muscat, J.; Richie, J.P., Jr. Free Radical Production and Characterization of Heat-Not-Burn Cigarettes in Comparison to Conventional and Electronic Cigarettes. Chem. Res. Toxicol. 2020. [CrossRef] [PubMed]

13. Protano, C.; Avino, P.; Manigrasso, M.; Vivaldi, V.; Perna, F.; Valeriani, F.; Vitali, M. Environmental Electronic Vape Exposure from Four Different Generations of Electronic Cigarettes: Airborne Particulate Matter Levels. Int. J. Environ. Res. Public Health 2018, 15, 2172. [CrossRef]

14. Protano, C.; Manigrasso, M.; Avino, P.; Sernia, S.; Vitali, M. Second-hand smoke generated by new electronic device (IQOS and e-cigs) and traditional cigarettes: Submicron particle behaviour in human respiratory system. Ann. Ig. 2016, 28, 109-112. [CrossRef]

15. Benowitz, N.L. Nicotine and coronary heart disease. Trends Cardiovasc. Med. 1991, 1, 315-321. [CrossRef]

16. Protano, C.; Manigrasso, M.; Avino, P.; Vitali, M. Second-hand smoke generated by combustion and electronic smoking devices used in real scenarios: Ultrafine particle pollution and age-related dose assessment. Environ. Int. 2017, 107, 190-195. [CrossRef] [PubMed]

17. Münzel, T.; Hahad, O.; Kuntic, M.; Keaney, J.F.; Deanfield, J.E.; Daiber, A. Effects of tobacco cigarettes, e-cigarettes, and waterpipe smoking on endothelial function and clinical outcomes. Eur. Heart J. 2020. [CrossRef] [PubMed]

18. Pataka, A.; Kotoulas, S.; Chatzopoulos, E.; Grigoriou, I.; Sapalidis, K.; Kosmidis, C.; Vagionas, A.; Perdikouri, E.I.; Drevelegas, K.; Zarogoulidis, P.; et al. Acute Effects of a Heat-Not-Burn Tobacco Product on Pulmonary Function. Medicina (Kaunas) 2020, 2, 292. [CrossRef] [PubMed]

19. Başaran, R.; Güven, N.M.; Eke, B.C. An Overview of iQOS®as a New Heat-Not-Burn Tobacco Product and Its Potential Effects on Human Health and the Environment. Turk. J. Pharm. Sci. 2019, 16, 371-374. [CrossRef]

20. Adriaens, K.; Gucht, D.V.; Baeyens, F. IQOSTM vs. e-Cigarette vs. Tobacco Cigarette: A Direct Comparison of Short-Term Effects after Overnight-Abstinence. Int. J. Environ. Res. Public Health 2018, 15, 2902. [CrossRef]

21. Forster, M.; McAughey, J.; Prasad, K.; Mavropoulou, E.; Proctor, C. Assessment of tobacco heating product THP1.0. Part 4: Characterisation of indoor air quality and odour. Regul. Toxicol. Pharmacol. 2018, 93, 34-51. [CrossRef] [PubMed]

22. Marcham, C.L.; Springston, J.P. Electronic cigarettes in the indoor environment. Rev. Environ. Health 2019, 34, 105-124. [CrossRef] [PubMed]

23. Friedman, A.S.; $\mathrm{Xu}, \mathrm{S}$. Associations of Flavored e-Cigarette Uptake With Subsequent Smoking Initiation and Cessation. JAMA Netw. Open 2020, 3, e203826. [CrossRef]

24. Protano, C.; Manigrasso, M.; Cammalleri, V.; Biondi Zoccai, G.; Frati, G.; Avino, P.; Vitali, M. Impact of Electronic Alternatives to Tobacco Cigarettes on Indoor Air Particular Matter Levels. Int. J. Environ. Res. Public Health 2020, 17, 2947. [CrossRef] [PubMed]

25. International Agency for Research on Cancer. Monographs on the Evaluation of Carcinogenic Risks to Humans; WHO Press: Lyon, France, 2015.

26. Nguyen, J.L.; Yang, W.; Ito, K.; Matte, T.D.; Shaman, J.; Kinney, P.L. Seasonal Influenza Infections and Cardiovascular Disease Mortality. JAMA Cardiol. 2016, 1, 274-281. [CrossRef]

27. Shen, Y.S.; Lung, S.C. Multiple impacts and pathways of urban form and environmental factors on cardiovascular mortality. Sci. Total Environ. 2020, 738, 139512. [CrossRef]

28. Braun, M.; Koger, F.; Klingelhöfer, D.; Müller, R.; Groneberg, D.A. Particulate Matter Emissions of Four Different Cigarette Types of One Popular Brand: Influence of Tobacco Strength and Additives. Int. J. Environ. Res. Public Health 2019, 16, 263. [CrossRef]

29. Manigrasso, M.; Protano, C.; Vitali, M.; Avino, P. Where Do Ultrafine Particles and Nano-Sized Particles Come From? J. Alzheimers Dis. 2019, 68, 1371-1390. [CrossRef] 
30. Manigrasso, M.; Vitali, M.; Protano, C.; Avino, P. Temporal evolution of ultrafine particles and of alveolar deposited surface area from main indoor combustion and non-combustion sources in a model room. Sci. Total Environ. 2017, 598, 1015-1026. [CrossRef]

31. Manigrasso, M.; Vitali, M.; Protano, C.; Avino, P. Ultrafine particles in domestic environments: Regional doses deposited in the human respiratory system. Environ. Int. 2018, 118, 135. [CrossRef]

32. Hiscock, R.; Silver, K.; Zatoński, M.; Gilmore, A.B. Tobacco industry tactics to circumvent and undermine the menthol cigarette ban in the UK. Tob. Control 2020. [CrossRef] [PubMed]

33. Mishra, S. Are e-cigarettes beneficial for public health: Hume's guillotine-The debate continues? Indian Heart J. 2017, 69, 810-813. [CrossRef] [PubMed]

34. Blackwell, A.K.M.; De-Loyde, K.; Brocklebank, L.A.; Maynard, O.M.; Marteau, T.M.; Hollands, G.J.; Fletcher, P.C.; Attwood, A.S.; Morris, R.W.; Munafò, M.R. Tobacco and electronic cigarette cues for smoking and vaping: An online experimental study. BMC Res. Notes 2020, 13, 32. [CrossRef] [PubMed]

35. Schober, W.; Fembacher, L.; Frenzen, A.; Fromme, H. Passive exposure to pollutants from conventional cigarettes and new electronic smoking devices (IQOS, e-cigarette) in passenger cars. Int. J. Environ. Res. Public Health 2019, 222, 486-493. [CrossRef]

36. Tzortzi, A.; Teloniatis, S.; Matiampa, G.; Bakelas, G.; Tzavara, C.; Vyzikidou, V.K.; Vardavas, C.; Behrakis, P.; Fernandez, E. TackSHS Project Investigators. Passive exposure of non-smokers to E-Cigarette aerosols: Sensory irritation, timing and association with volatile organic compounds. Environ. Res. 2020, 182, 108963. [CrossRef] [PubMed]

37. Papaefstathiou, E.; Stylianou, M.; Agapiou, A. Main and side stream effects of electronic cigarettes. J. Environ. Manag. 2019, 238, 10-17. [CrossRef] [PubMed]

38. Fait, B.W.; Thompson, D.C.; Mose, T.N.; Jatlow, P.; Jordt, S.E.; Picciotto, M.R.; Mineur, Y.S. Menthol disrupts nicotine's psychostimulant properties in an age and sex-dependent manner in C57BL/6J mice. Behav. Brain Res. 2017, 334, 72-77. [CrossRef]

39. Girvalaki, C.; Tzatzarakis, M.; Kyriakos, C.N.; Vardavas, A.I.; Stivaktakis, P.D.; Kavvalakis, M.; Tsatsakis, A.; Vardavas, C. Composition and chemical health hazards of the most common electronic cigarette liquids in nine European countries. Inhal. Toxicol. 2018, 30, 361-369. [CrossRef]

40. Kim, H.; Lim, J.; Buehler, S.S.; Brinkman, M.C.; Johnson, N.M.; Wilson, L.; Cross, K.S.; Clark, P.I. Role of sweet and other flavours in liking and disliking of electronic cigarettes. Tob. Control 2016, 25, ii55-ii61. [CrossRef]

41. Kuga, K.; Ito, K.; Chen, W.; Wang, P.; Kumagai, K. A numerical investigation of the potential effects of e-cigarette smoking on local tissue dosimetry and the deterioration of indoor air quality. Indoor 2020. [CrossRef]

42. Litt, M.D.; Duffy, V.; Oncken, C. Cigarette smoking and electronic cigarette vaping patterns as a function of e-cigarette flavourings. Tob. Control 2016, 25, ii67-ii72. [CrossRef] [PubMed]

43. Mead, E.L.; Duffy, V.; Oncken, C.; Litt, M.D. E-cigarette palatability in smokers as a function of flavorings, nicotine content and propylthiouracil (PROP) taster phenotype. Addict. Behav. 2019, 91, 37-44. [CrossRef] [PubMed]

44. Oncken, C.A.; Litt, M.D.; McLaughlin, L.D.; Burki, N.A. Nicotine concentrations with electronic cigarette use: Effects of sex and flavor. Nicotine Tob. Res. 2015, 17, 473-478. [CrossRef] [PubMed]

45. Voos, N.; Smith, D.; Kaiser, L.; Mahoney, M.C.; Bradizza, C.M.; Kozlowski, L.T.; Benowitz, N.L.; O'Connor, R.J.; Goniewicz, M.L. Effect of e-cigarette flavors on nicotine delivery and puffing topography: Results from a randomized clinical trial of daily smokers. Psychopharmacology 2020, 237, 491-502. [CrossRef]

46. Centers for Disease Control and Prevention (US); National Center for Chronic Disease Prevention and Health Promotion (US); Office on Smoking and Health (US). How Tobacco Smoke Causes Disease: The Biology and Behavioral Basis for Smoking-Attributable Disease: A Report of the Surgeon General; Centers for Disease Control and Prevention (US): Atlanta, GA, USA, 2010. Available online: https://www.ncbi.nlm.nih.gov/books/NBK53017/ (accessed on 15 July 2020).

47. Biondi-Zoccai, G.; Carnevale, R.; Vitali, M.; Tritapepe, L.; Martinelli, O.; Macrina, F.; Bullen, C.; Peruzzi, M.; Cavarretta, E.; Marullo, A.G.; et al. A randomized trial comparing the acute coronary, systemic, and environmental effects of electronic vaping cigarettes versus heat-not-burn cigarettes in smokers of combustible cigarettes undergoing invasive coronary assessment: Rationale and design of the SUR-VAPES 3 trial. Minerva Cardioangiol. 2020. [CrossRef] 
48. Lelieveld, J.; Münzel, T. Air pollution, the underestimated cardiovascular risk factor. Eur. Heart J. 2020, 41, 904-905. [CrossRef]

49. Unger, M.; Unger, D.W. E-cigarettes/electronic nicotine delivery systems: A word of caution on health and new product development. J. Thorac. Dis. 2018, 10, S2588-S2592. [CrossRef]

50. Blount, B.C.; Karwowski, M.P.; Shields, P.G.; Morel-Espinosa, M.; Valentin-Blasini, L.; Gardner, M.; Braselton, M.; Brosius, C.R.; Caron, K.T.; Chambers, D.; et al. Lung Injury Response Laboratory Working Group. Vitamin E Acetate in Bronchoalveolar-Lavage Fluid Associated with EVALI. N. Engl. J. Med. 2020, 382, 697-705. [CrossRef]

51. Nitzkin, J.L. The Case in Favor of E-Cigarettes for Tobacco Harm Reduction. Int. J. Environ. Res. Public Health 2014, 11, 6459-6471. [CrossRef]

(C) 2020 by the authors. Licensee MDPI, Basel, Switzerland. This article is an open access article distributed under the terms and conditions of the Creative Commons Attribution (CC BY) license (http://creativecommons.org/licenses/by/4.0/). 